\title{
A!
}

This is an electronic reprint of the original article.

This reprint may differ from the original in pagination and typographic detail.

Nelimarkka, Matti; Laaksonen, Salla Maaria; Semaan, Bryan

\section{Social media is polarized, social media is polarized}

Published in:

DIS 2018 - Proceedings of the 2018 Designing Interactive Systems Conference

DOI:

$10.1145 / 3196709.3196764$

Published: 08/06/2018

Document Version

Peer reviewed version

Please cite the original version:

Nelimarkka, M., Laaksonen, S. M., \& Semaan, B. (2018). Social media is polarized, social media is polarized:

Towards a new design agenda for mitigating polarization. In DIS 2018 - Proceedings of the 2018 Designing

Interactive Systems Conference (pp. 957-970). ACM. https://doi.org/10.1145/3196709.3196764

This material is protected by copyright and other intellectual property rights, and duplication or sale of all or part of any of the repository collections is not permitted, except that material may be duplicated by you for your research use or educational purposes in electronic or print form. You must obtain permission for any other use. Electronic or print copies may not be offered, whether for sale or otherwise to anyone who is not an authorised user. 


\section{Social Media Is Polarized, Social Media Is Polarized: Towards a New Design Agenda for Mitigating Polarization}

\author{
Matti Nelimarkka \\ Aalto University, HIIT
}

\author{
Salla-Maaria Laaksonen \\ University of Helsinki
}

\author{
Bryan Semaan \\ Syracuse University
}

\begin{abstract}
Social media platforms have often been described as online spaces supporting political discourse. However, online discussions are often polarized; people tend to commune with those who are ideologically similar to them. The HCI response to this phenomenon has been to purposefully expose people to diverse viewpoints. This common design agenda is supported through analysis of link sharing, yet little attention has been paid to how users discuss these links. Therefore, the common design agenda may not mitigate polarization. We study the emergent discourse in 10 Finnish migration-related Facebook groups and examine how the same links are shared and discussed across anti- and pro-migration camps. Qualitative analysis of the posts and comments revealed that shared media links do not bridge polarized groups with regard to worldviews and opinions. We then demonstrate alternative design opportunities to resolve this issue and begin to develop a new design agenda to mitigate polarization.
\end{abstract}

\section{ACM Classification Keywords}

H.5.m. Information Interfaces and Presentation (e.g. HCI): Miscellaneous

\section{Author Keywords}

polarization; selective exposure; echo chambers; filter bubble

\section{INTRODUCTION}

It is well established that in the context of online political activities, certain communicative acts invite the formation of an ad hoc public sphere - an online space where any individual is free to exchange political information and ideas with others [60]. For example, users of social media services such as Facebook and Twitter can participate by joining political groups, exchanging information (e.g., links to media articles) and opinions, or engaging in political discourse on various topics $[6,4,61,60]$. This leads to questions about the impact of social media services in terms of their ability to facilitate information exchange and political discourse.

As evidenced by the 2016 United States (US) Presidential election or Brexit - wherein the United Kingdom where the citizens were strongly divided about the vote to leave the European Union (EU) - Western society has been plagued

Permission to make digital or hard copies of all or part of this work for personal or classroom use is granted without fee provided that copies are not made or distributed for profit or commercial advantage and that copies bear this notice and the full citation on the first page. Copyrights for components of this work owned by others than the author(s) must be honored. Abstracting with credit is permitted. To copy otherwise, or republish, to post on servers or to redistribute to lists, requires prior specific permission and/or a fee. Request permissions from permissions@acm.org.

DIS '18, June 9-13, 2018, , Hong Kong

(C) 2018 Copyright held by the owner/author(s). Publication rights licensed to ACM ISBN 978-1-4503-5198-0/18/06 . .\$15.00

DOI: https : //doi .org/10.1145/3196709. 3196764 by increased polarization. That is, people tend to commune with those ideologically similar to them, while sharing media and engaging in discourse that predominantly supports their own perspectives. The impacts of this ideological distance include a divergence of attitudes, toward extremes, and a lack of common ground [35]. Scholars attribute the increase in polarization to online technologies, since they allow likeminded people to find each other irrespective of geographical distance, form groups [8], state opinions that get spread by their networks and hence strengthen the biases thereof [56], and algorithmically curate content in line with participants' interests - hence potentially leaving out alternative perspectives [21]. The research community has framed this phenomenon as selective exposure [1, 37, 39], echo chambers [27, 66], and filter bubbles [50] in online spaces.

The polarization phenomenon has led researchers to explore design opportunities for balancing the use of media and, in turn, exposing people to diverse perspectives, with particular emphasis on news media $[10,40,52]$. Given how much effort is put to investigate this line of design, we call it the Common Design Agenda. However, link and network analysis $[1,27,39]$, which has motivated many of the systems-design efforts to balance media, does not capture how people receive the information linked to or react to it. The affordances of social media allow users to not only share links but engage in discourse around links through reflection, agreement, and disagreement. We argue that more attention must be paid to the ways in which users react to links. This should yield more insightful perspectives on traditional link analysis and describe how people encounter links - that is, such analysis will help to create valuable insight for design of interactive systems to support the dissemination of and conversation around varied information and opinions.

To empirically investigate the Common Design Agenda, we explored linking and communication practices in Finnish Facebook groups related to immigration and the emergent refugee crisis. The refugee crisis has affected Finland, as it has the rest of Europe. Finland is a unique context for examining polarization for three critical reasons. Firstly, it is characterized by Nordic values manifested in high societal trust (e.g., high trust among citizens and between citizens and the government [9]). Secondly, few issues have polarized the Finnish public at national level historically, with immigration and asylumseekers being rare instances of this emergent phenomenon [3, 71]. Lastly, the majority of scholarship exploring polarization has been conducted in the US political context $[1,35,56]$; this serves as an important point of departure for understanding online political communication around polarizing issues. 
Following our empirical investigation, we develop alternatives to the Common Design Agenda. Our work presents different design opportunities and begins to map out a framework which can be used to mitigate polarization. Importantly, the design agenda we develop is not meant to serve as a final vision, but already demonstrates several opportunities available for designers. Thus, it questions why the focus within human-computer interaction has been on the Common Design Agenda.

In the sections that follow, we firstly outline relevant work within new media research on polarization. Following this, we present the empirical investigation challenging the Common Design Agenda. We describe our case, data, and methods in detail, then present results. Next, we discuss opportunities outside the current Common Design Agenda. Finally, we discuss the implications of our work for shifting towards a new design agenda for mitigating polarization, and we outline limitations of our study.

\section{BACKGROUND}

\section{The Social Implications of Polarization}

Polarization is increasing of ideological distance between individuals or groups [35]. It typically happens when people become divided into groups with opposing perspectives - for example, people who are "pro-choice" (i.e., who believe in a right to have an abortion) and "pro-life" (i.e., who believe abortion should be illegal). In the US, political polarization between political parties [35] and in media [56] has grown, but research regarding ordinary citizens shows more mixed results. It is not clear whether citizens are becoming more polarized or polarization is only taking place among extremists $[15,35,56]$. While more of the research has been done in the US, Europe is not an exception for the effects of polarization [12, 73, 71].

The general consensus is that polarization is harmful to society, and researchers have identified three main elements in support of this assertion. Firstly, at political party level, polarization can lead to emergent challenges for policy-making, since finding suitable alternatives that appease people across polarized groups can be difficult. Also, polarization may decrease interest and trust in political decision-making [35]. Thirdly, great disagreement on issues (and polarization) makes it difficult to accept alternative policy decisions even if such decisions have come about through a fair process [74]. Therefore, social scientists who have studied polarization have warned of the effects of polarization and the emergence of like-minded groups whose members engage only with one another. Moreover, scholars have increasingly expressed worries about the effects and social implications of the Internet and social media with regard to polarization [56].

Sunstein [66], drawing on Negroponte's work, warned of potential negative ramifications of Internet technologies in terms of polarization. He hypothesized that Internet use would lead to increased polarization among the public as it makes it easier for people to seek information and opinions, and form camps, with like-minded others. In channeling Sunstein's hypothesis, several scholars have examined how to mitigate polarization $[52,40,42,41,60,18,17]$. In the sections that follow, we first present empirical research on online communities and polarization, discuss the challenges and limits of this literature, and finally, review how the common design agenda is based on only a partial perspective on polarization in online communities.

\section{Online Communities and Polarization}

Studies of the effects of Internet technologies on polarization have focused heavily on network structures and linking behavior, or how users network with other users and share or consume news media in the form of hyperlinks. Among the first of these studies, Adamic and Glance's work [1] showed how political blogs tend to link to political blogs ideologically aligned with them. For example, they found that in the US, liberal blogs linked to other liberal blogs and conservative blogs linked to other conservative blogs. This study led to the emergence of research focused on polarizing effects of social media and online news reading practices Hence, scholars have since identified the emergence of echo chambers [28] and filter bubbles [51]. Here, the main claim is that, through the use of social and new media, people are coalescing with other like-minded people and circulating and reinforcing the same views and opinions, which, in turn, never get contested or questioned.

Other scholars have focused on the impact of algorithms and algorithmic curation for how information moves through social media and on how this can lead to polarization. Pariser [51] argues that echo chambers are reinforced by algorithms governing the flow of content in social-networking services. Recent empirical work has demonstrated the effect of algorithms in contributing to the creation of echo chambers and filter bubbles. For example, in a study of online link-sharing in the context of climate change, Itkonen [26] showed that Facebook users tend to have online friends who share their concerns and that Facebook's algorithm often displays information that reinforces the same viewpoint. Similarly, using Twitter data from 3.8 million users, Barberá et al. [2] showed that echo-chamber effects are present particularly in connection with political issues. Overall, empirical analysis shows that people who share ideological beliefs are more likely to exchange information around political topics with like-minded others.

These observations can be seen in the common design agenda as scholars have focused on mitigating these issues by balancing news reading and breaking the echo chambers caused by polarization. However, the evidence for selective exposure that is, of a tendency for users to consume media compatible with already held attitudes - is mixed. For example, research has found that both Twitter and Facebook users link to sites with various ideologies [39, 27, 60], whereas in political blogs people stick more to a particular ideology [37].

More recent scholarship has aimed to move beyond the classic study of polarization in linking behavior. Researchers have started to explore the ways in which polarized groups consume information, and they have found that, while groups differ in views, their consumption of media is similar. Meraz et al. [37] observed that the domains shared between two groups - which constituted $21 \%$ of all domains - were mostly 
traditional media organizations. They hence suggested these media organizations to have a significant role in bridging various communities. Jacobson et al. [27] found that comments on the Facebook pages of two partisan television channels shared similar domains for over $45 \%$ of the links in the two communities. This indicates that, while media use might be polarized, people still use the same sources of information to make their arguments and claims in the comments. These findings challenge the focus of the common design agenda as this behavior might occur naturally.

\section{Beyond Analysis of Linking: Discussing Links}

Consumption of news media through social media is not purely based on link-sharing. Rather, social media platforms afford two significant features that move beyond simply sharing information. Firstly, the platforms allow for framing and expressing the links in one's preferred way and for discussions based on a combination of those links with personal perspectives. Secondly, the links shared through social media stem from individuals' decision to share them via social media [29]. Thus, link-sharing is a more strategic action; that is, an individual wishes to share this particular link with a particular community.

Therefore, the research on media exposure and on polarization must accommodate the affordances provided by social media services. However, the literary on online polarization does not currently cover these aspects well covered as the analysis has focused on the use of links.

For example, research on news sites and those sites' comment systems has shown the importance of user comments. Comments are often read for gaining insights into the community's reaction to the news [13]. Furthermore, it has been found that "user-generated comments accompanying news stories can significantly alter other participants' beliefs about what other members of society think" [36]. Furthermore, an experimental investigation by Messing and Westwood [38] demonstrated that social endorsements alter sharing and consumption of news online. Using an experimental setting that simulated a Facebook newsfeed, they argued that, while social networking services expose people to a wider variety of news via their social contacts, social endorsements by contacts affect what one chooses to read.

However, such studies proceed from the premise that news consumption takes place in the individuals' news feeds and do not take into account the social effect of online groups, nor do they investigate the discussions that take place in relation to the news. For example, Gilbert and colleagues, examining blog comments, found that political blogs isolate readers from dissenting opinions [20]. Therefore, the common design agenda must further take into account the social context of information processing, not just the ability to account for the balance of links shared.

\section{How $\mathrm{HCl}$ has aimed to mitigate Polarization?}

Since polarization is considered harmful for society, research in $\mathrm{HCI}$ and related disciplines has examined how to mitigate it through design endeavors [52, 40, 42, 41]. While there is research indicating that echo chambers are not always a result of underlying technology design decisions or algorithmic bias but rather on group processes [46, 24, 11], the work has been focused on "nudging" the users and applying behavioral change techniques.

The NewsCube [52] study showed readers several aspects of a given story by collecting various news items and automatically extracting aspects of them. It also helped readers see how stories they had already read had different aspects and thereby informed readers about the existence of media bias. It was shown that the design led readers to read more stories and, therefore, broaden their perspectives. The NewsCube design has also fostered more extensive system development, including a browser widget with similar goals [10].

The BALANCER SYSTEM [40] was designed to visualize the overall balance of media consumption - the number of liberal and conservative Web sites the user had visited. The system was able to convince participants to visit other sites to some degree, but the authors warned about over-generalizing from these findings, because of the biased sample of study participants.

Futhermore, Munson et al. [41, 42] examined methods to expose additional viewpoints in news aggregation, particularly methods to show content the user does not agree with in the interface. They showed that those with a preference for diversityseeking preferred systems that showed 60\% agreeable content, whereas non-diversity-seeking users favored situations featuring only agreeable content most. Furthermore, they showed that the alternative methods for presenting non-agreeable content, sorting the content such that agreeable content is first or highlighting agreeable content, did not increase satisfaction. Therefore, they concluded that there are ways to improve exposure but that there is a cost in user satisfaction among people who do not seek diverse opinions.

Beyond changes to media consumption patterns, only a few proposals have been made and they seem to also drive from the analysis on lack of different perspectives. Semaan et al. [59, 60] showed that some people are interested in using social media for discussion beyond their own camps. In particular, they studied users who used multiple social media sites to reach different audiences and seek other opinions. They concluded that such uses should be further supported via development of systems that facilitate finding discussion from several social media systems. Similarly, polarization-aware recommendation systems have been discussed. The goal with such work is to develop recommendations as to how to diversify a user's network $[18,17]$. The aim is to recommend that two people, with different opinions, discuss their perspectives, choosing these people from only mildly polarized populations.

The tools on the common design agenda have been focused on providing more information to users. However, these efforts have not accounted for the social interaction and framing carried out in the online communities. Those focusing on social interaction, meanwhile, have aimed to increase interaction between the polarized lines. However, the Common Design Agenda has not addressed the question of how to decrease 
polarization by framing the shared links in different ways and therefore, building common ground further. It seems that the common design agenda has stagnated on the idea of recommending content or contacts across polarized groups, but has not considered alternative approaches.

\section{CHALLENGING THE COMMON DESIGN AGENDA: A FIELD STUDY ON POLARIZED DISCUSSION}

Our aim in this section is to demonstrate the potential failure of the ideas pushed forward through the Common Design Agenda. Based on the critique presented above, we draw on an empirical case to answer two questions. First, to establish polarization we examine the link sharing practices in politically opposing Facebook groups and study

Research question 1: To what degree cross-camp link sharing occurs naturally and what type of content is common between these groups?

Following this and to examine the sustainability of the Common Design Agenda we analyze comment threads on these links. The idea of Common Design Agenda is to expose people to news stories and information sources outside their own perspective. This can be seen through Facebook posts with same link shared to both camps and the discussion emerging in those posts. Therefore, we sought to answer this open-ended question:

Research question 2: How is the discussion on the common links different from links shared only within the camp?

This research setup mimics closely the gist of the Common Design Agenda: ensuring that people read the perspectives of opposing camp and reflect on it. This allows us to gauge the common design agenda in a naturalistic settings, seeing what might take place when both camps are proposed similar links. To our knowledge, the analysis on emergent discourse on polarized topics that surrounds links on social media platforms is a novel methodological perspective. The novel methodological perspective provides insights into problems of the common design agenda in a natural setting and therefore, make a contribution to the ongoing debate on online polarization.

\section{The Research Setting: The Finnish Context}

We have chosen to study Finland in response to the extensive research conducted in the US. The political context for our study is one of emerging polarization. The topic of migration has been less prominent in Finnish society and, therefore, has less historical context that could enter in than does the United States with its marked polarization across party lines. It has been argued that before 2015, there was little political polarization in Finnish society [3, 71]. Furthermore, the topic examined has high societal importance both in Finland and in Europe at large.

Since 2015, Finland has, not unlike other European countries, experienced a rise in the number of forced migrants, or refugees, from the Middle East and Africa who travel across the continent and often seek asylum or permanent residence [58]. In total, EU member states received over 1.2 million asylum applications in 2015 alone, which represents a twofold increase from the previous doubling, in 2014 [14]. According to the Finnish Immigration Authority, Finland alone received almost 32,500 asylum-seekers in 2015, up from 3,651 in 2014. The rising number of refugees seeking asylum has prompted much media coverage, citizen activities, demonstrations, and debate on various platforms (including social media, especially in the Facebook service). Therefore, the Finnish public has mobilized both in support of and in resistance to the influx of refugees to the country.

In its politics, Finland is a multi-party nation with a total of nine parties in the parliament. As a Nordic state, Finland has historically been characterized by a lack of contentious politics whereby few issues have polarized the public. Today, there exist only four political issues that serve to divide the public: support for traditional values, cultural and social diversity, economic freedom, and economic equality [72]. The economic downturn in the late 2000s led to long-term recession. However, these issues do not typically form strong dividing lines, since citizens can at the same time support economic freedom and economic equality [72, 48, 65, 64].

In this country with high societal trust [9], the most frequently used sources for political information are television news (considered a highly important or important politics-information source by $58 \%$ of citizens) and the newspaper (44\%). The major news sources aim to provide high-quality journalistic products and have agreed to follow ethics guidelines for journalism. Strongly biased media sites are not part of Finland's mainstream media, nor do the main media outlets openly espouse any political stances. social media channels serve as a major venue for political information for approximately $15 \%$ of the citizens [23]. The Internet is used on a daily basis by $79 \%$ of the population, $74 \%$ of people use it to read news, $47 \%$ use social media services daily, and $11 \%$ use this channel for political or civic purposes. social media use is somewhat biased towards people under 55, the more educated, and people in urban areas [63]. This level of use makes the study of social media and polarization sustainable endeavour.

\section{Community Selection and Collection of Data}

To explore the relationships between polarization, link-sharing, and link-commenting behavior, we compiled a dataset from 10 Finnish Facebook communities. This decision reflects the online communication practices of the Finnish population: Facebook is much more used than Twitter in Finland [57]. Within Facebook, there are two types of online communities: groups and pages. The Facebook groups create a "news feed" for only that group, in which all group members can post and comment on content. Facebook groups can be publicly open or hidden from the public; for reasons of research ethics, we focus on public groups only. The Facebook pages are "profile pages" for a particular cause or for an organizational actor. While pages are driven more by the administration team, the groups are community-driven.

The 10 communities we selected for analysis were the largest ones on expert-sourced lists of pro-immigration and antiimmigration communities, five for each "camp" (see Table 1) (we will henceforth use the term "camp" to refer to a set of 


\begin{tabular}{|c|c|c|}
\hline ID & Description & Total posts \\
\hline A1 & $\begin{array}{l}\text { Anti-immigration movement that aims to close borders to asylum-seekers. Born in } \\
\text { response to the refugee crisis in fall } 2015 \text {. }\end{array}$ & 22,544 \\
\hline A2 & Conversation group that promotes Finland as being a place for Finns only. & 14,576 \\
\hline A3 & $\begin{array}{l}\text { Anti-immigration movement aiming to achieve the status of registered political party. } \\
\text { Born in response to the refugee crisis in fall } 2015 \text {. }\end{array}$ & 5,231 \\
\hline A4 & $\begin{array}{l}\text { Anti-immigrant street-patrol group founded in October } 2015 \text { and registered as an as- } \\
\text { sociation in January } 2016 \text {. }\end{array}$ & 1,478 \\
\hline A5 & More protest-organization-focused sub-group of A3 & 1,411 \\
\hline P1 & Network-like association that works against racism and xenophobia. & 19,867 \\
\hline P2 & $\begin{array}{l}\text { Social movement organizing refugee-related activism and concrete help, from accom- } \\
\text { modation to volunteer translation. }\end{array}$ & 4,833 \\
\hline P3 & $\begin{array}{l}\text { Facebook group promoting an international Finland and objecting to racism, led by a } \\
\text { non-profit organization. Founded in } 2010 \text {. }\end{array}$ & 3,063 \\
\hline P4 & Facebook group that objects to hate speech. & 1,561 \\
\hline P5 & Facebook group that objects to racism in Finland. & 1,540 \\
\hline
\end{tabular}

Table 1: Descriptions of the communities studied

five communities with a similar attitude). The six experts were academics who had previously worked on topics related to immigration, online racism, and social media in general; for example, some had done fieldwork with media organizations on hate speech. In total, the experts identified 40 pro-immigration and 15 anti-immigration Facebook communities, which were whittled down to 10 communities for the reasons previously mentioned. The differences were discussed when experts disagreed, but the list was built collectively.

The dataset is composed of 73,041 posts within these 10 communities, spanning April 2010 to February 2017. Each post has accompanying details such as the "likes" and other reactions it garnered, all comments, comments on comments, and the "likes" for those, alongside the text content and links in the original post. The data were collected from the Facebook API by means of a custom-built tool. ${ }^{1}$ With regard to research ethics, we acknowledge that not all that is public on the Web should be made available for research [5], particularly in studying a politically heated topic such as immigration. Therefore, we do not analyze any individuals in the data. While we use quotes to demonstrate our findings, during translation from Finnish we ensured that they were properly anonymized and decontextualized to make it more difficult to pinpoint anyone posting the comments.

\section{Analysis Approaches}

We used a mixed-methods approach encompassing both qualitative and quantitative elements. Our research is data-driven research [31] since we did not test given hypotheses, instead changing our analysis approach between the use of explanatory and confirmatory tools during the research process. Overall, we conducted classification of the data in line with three main criteria, related to link types (RQ1), characteristics of the message (RQ2), and the relationship between the message and the link (RQ2).

RQ1 required classification of the links shared. Firstly, we conducted open coding on a sample of the domain content to produce coding categories (see Table 2). We then compared our proposed categories to those used in previous work [37] and aligned our categories with those when this was necessary and possible. After this, we proceeded to code a larger set of domains. Since this stage required extensive manual work, we chose to classify only all domains that were used by both camps $(n=539)$ and the half of the domains with the highest number of links $(n=244)$ (five or more links). After this, the rest of the domains were skimmed by the researchers and

\footnotetext{
${ }^{1}$ See https://github. com/HIIT/hybra-someloader.
}

those identified were classified. In total, this method captures $22 \%$ of all domains and $97 \%$ of the links present in the dataset, because the link frequencies follow a power law. We consider this coverage sufficient for further analysis. During the coding, when in doubt about the content, we checked the site via Wikipedia, Web of Trust (https://www.mywot.com/), and Media BiasFact Check (https://mediabiasfactcheck. com/) to help assign the site to a category. Two researchers independently conducted analysis of the whole dataset to ensure the validity of the classification. Disagreements were discussed and agreed upon case-specifically.

We answered RQ1 by examining the differences in linksharing in our data. We examined the common links (links featured in both camps) in comparison to links shared only within a single camp. For both of these questions, we first conducted a $\chi^{2}$ test to examine whether differences exist in the distribution of news sources. To examine detailed analysis on what causes these differences, we conducted further analysis with a two-sample (proportional) $z$-test with Bonferroni correction to account for the large number of comparisons made.

To understand the discussion (RQ2), we classified contributions in line with the relationship to the URL and the type of statements made (see Table 3 ). The type-of-statements classification was adapted from the literature [62] but expanded to separate out also factual claims based on referenced facts, anecdotal evidence, personal experience, and threat scenarios (marked in the table with ${ }^{\star}$ ). We tested and developed the categorization via two of the authors classifying a sample set of data simultaneously. Again, on account of the large total number of posts, we could not analyze all the posts. Instead, we used a random sample of posts that included a link common to the two camps and another random sample of posts with camp-specific URLs. Of the posts that had a common URL, we selected $2 \%$ of the content (961 posts or comments) for analysis. Of the posts with no common URL, we selected at random, in total, 559 posts or comments for analysis. For the relationship to the URL, we achieved a low but acceptable value in reliability measurements $(\kappa=0.58$, agreement $72 \%)$. For statement types, we performed comparison for each statement separately (since the choices there were non-exclusive) and achieved $\kappa$ values of $0.55-0.67$ and agreement between $86 \%$ and $95 \%$. Since $\kappa$ is considered a conservative measurement, it has been argued that even $\kappa>0.4$ can be applied [68]. Values around $\kappa \approx 0.6$ indicate moderate to substantial agreement [34], and we argue that these values are sufficient to warrant further analysis.

Our strategy for answering RQ2 followed the same analysis approach as that for RQ1: we examined differences in the communities by utilizing $\chi^{2}$ testing and then a two-sample $z$-test. Our further analysis focuses on links common between the camps; motivated by RQ1, we were interested in examining whether opinions on these links diverge or converge. To ascertain this, we determined the position taken most often on the link in the pro-immigration and in the anti-immigration camp. Discussion of the link on both camps was aggregated only to the majority position. Next, we compared the types of 


\begin{tabular}{|c|c|c|}
\hline Category & Subcategory & Examples \\
\hline $\begin{array}{l}\text { Media Sites from journalistic organizations that } \\
\text { have salaried staff. The Web site is often }\end{array}$ & National media Journalistic products with national or otherwise general-interest focus within Finland. & $\begin{array}{l}\text { Helsingin Sanomat (the largest-circulation newspa- } \\
\text { per) }\end{array}$ \\
\hline $\begin{array}{l}\text { complementary to other forms of distributing news, } \\
\text { such as a newspaper or broadcasts (e.g., radio), but }\end{array}$ & Local media Journalistic products that have more explicit regional focus within Finland. & $\begin{array}{l}\text { Salon Seudun Sanomat (a local paper for the town } \\
\text { of Salo) }\end{array}$ \\
\hline this is not mandatory. This corresponds to & Organization media Journalistic products published by a Finnish organization - e.g., a membership, employee, or stakeholder magazine. & Seurakuntalainen (a magazine for the state church) \\
\hline \multirow[t]{2}{*}{ Jacobson's "mainstream media" [27]. } & Political party media Journalistic products published by a Finnish political party. & Vihreä lanka (a party magazine for the Green party) \\
\hline & $\begin{array}{l}\text { International media Journalistic products published outside Finland. Note that these are not more explicitly classified as national, local, } \\
\text { organizational, and political groups' but, rather, represent all internationally focused media. }\end{array}$ & Aftonbladet, Expressen, NBC News, Politico \\
\hline News-like site & $\begin{array}{l}\text { Sites that publish news-like content in a format that resembles media but where the factuality of the content is questionable. This includes } \\
\text { clickbait sites, media sites that provide non-factual information, "alternative media" sites, and "fake news" sites. It partially corresponds to } \\
\text { "humour" [27] }\end{array}$ & Frontpagemag.com, Breitbart.com \\
\hline \multirow{6}{*}{$\begin{array}{l}\text { Non-governmental organizations Sites run by } \\
\text { non-governmental or non-profit organizations. } \\
\text { This corresponds to Jacobson's "NGO" [27] with } \\
\text { the exception of including political organizations } \\
\text { also. }\end{array}$} & Finnish NGO Non-profit organizations operating mainly in Finland or operating with money from Finnish citizens and organizations. & Save the Children Finland, Finnish Red Cross \\
\hline & $\begin{array}{l}\text { Finnish social movement Social movements and issue-based "organizations" not organized as well as the non-governmental organizations. } \\
\text { This class also involves causes, often related to the topic of migration. }\end{array}$ & refugees-welcome.fi \\
\hline & $\begin{array}{l}\text { Finnish political party Parties on the Finnish Ministry of Justice's list of parties (this is the definition of a political party in Finnish law) and } \\
\text { affiliated party organizations. }\end{array}$ & National Coalition Party \\
\hline & International organization Non-profit organizations operating mainly outside Finland. & Human Rights Watch, Open Society Foundations \\
\hline & International social movement Social movements and causes operating outside Finland. & Anonymous $\mathrm{HQ}$ \\
\hline & $\begin{array}{l}\text { International political party } \text { Political parties in some other country. } \\
\text {. }\end{array}$ & Republican Party \\
\hline $\begin{array}{l}\text { Governmental organizations Any local, national, } \\
\text { international, or multilevel government-operated }\end{array}$ & $\begin{array}{l}\text { Finnish governmental organization Organizations governing the citizens within Finland or providing the Finnish government with support } \\
\text { services to conduct such work. }\end{array}$ & $\begin{array}{l}\text { Finnish parliament, Ministry of Justice, City of } \\
\text { Helsinki }\end{array}$ \\
\hline organizations. This corresponds to Jacobson's & International governmental organization Organizations similar to Finnish governmental organizations but run by countries other than Finland. & White House, Bundestag \\
\hline "government organizational" [27]. & $\begin{array}{l}\text { Multilevel governmental organization Governing organizations working on a level above the national state. These work in multinational } \\
\text { collaboration on topics such as legislation, defense, and policy-making. }\end{array}$ & NATO, United Nations, European Union \\
\hline Person & Homepages, blogs, and other forms of online presence of a particular individual. & \\
\hline Company & $\begin{array}{l}\text { Homepages, blogs, and other forms of online presence for a commercial organization. This corresponds to Jacobson's category "commercial" } \\
\text { [27]. }\end{array}$ & Nokia.com, Apple.com \\
\hline Organization & $\begin{array}{l}\text { Homepages, blogs, and other forms of online presence for an organization that is not commercial but has a neutral stance on the topic. More } \\
\text { formal event Web sites too are considered to be organizations. }\end{array}$ & $\begin{array}{l}\text { University of Helsinki, Suomiareena (a yearly event } \\
\text { where policy questions are debated in public with } \\
\text { experts and the public) }\end{array}$ \\
\hline User-generated content & Sites that primarily display content produced by their users. This corresponds to Jacobson's "forum/social network" and "portal" [27]. & Tumblr, Twitter \\
\hline Unclassifiable & Information-presenting sites that cannot be classified as in any other category at domain level. & Dropbox user content \\
\hline
\end{tabular}

Table 2: Coding categories for domains

statements made between common links and links used only within one camp. For this, we again used $\chi^{2}$ testing, since we were studying nominal-scale variables.

We opted to use manual content classification instead of computational analysis for two main reason. Firstly, there are no validated computation tools for the Finnish language. We acknowledge that many elements we explored in the qualitative phase could have been examined automatically in other languages, such as English (for which sentiment-analysis tools (e.g., [67]) and, for example, LIWC exist [53]). Furthermore, many automated text-analysis tools produce rather rudimentary analyses, and a fine-grained investigation of statement types such as the one we conducted would not be possible with them for any language (see, e.g, [25]).

\section{Findings}

From the coding categories (see Table 2) we identified all links in all the posts in the pro-immigration and anti-immigration communities separately, and we extracted the domains used in both camps. As Figure 1 shows, many of the domains are unique to one particular group only. In fact, $74 \%$ of domains were not used beyond a single group, let alone between the camps. This supports the core idea of the Common Design Agenda: the groups, even within the same camp, have different media linking behaviors.

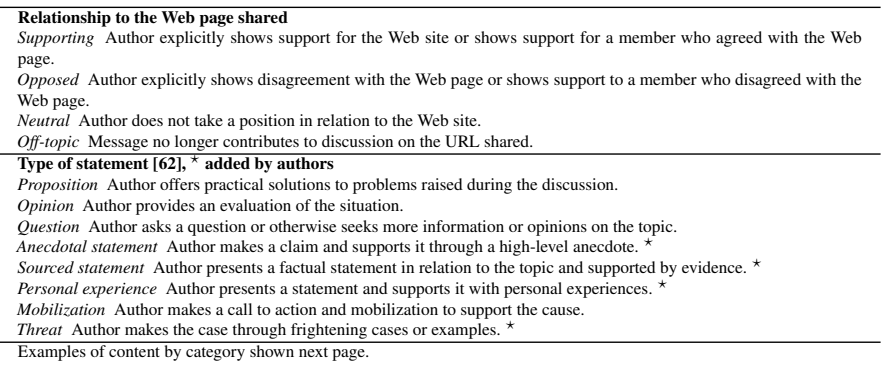

Table 3: Coding categories for messages

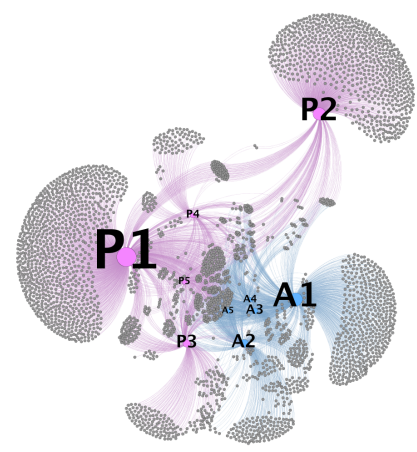

Figure 1: Selected communities and domains where they link RQ1: Common Links Are Different from Single Camp Links There are differences also between common links and what was shared only within a camp (see Table 4 , where significant results are marked with ${ }^{\oplus}$ and ${ }^{\ominus}$ ). In both communities, the links shared were more often to user-generated content and unclassified sources. They were less often from media sources, news-like sites, Finnish GOs, NGOs, SMs and parties, persons, companies, or organizations. Therefore, the national media, even while being the major source of information in both camps (accounting for $39 \%$ of all links examined), did not "connect" these camps. Instead, the camps shared different news stories even in an environment as small as Finland.

Furthermore, we conclude that, from this perspective, the media environment is highly fragmented. The total number of shared links in common was small $(1.9 \%, n=852)$. Both camps were equally active in linking to common sources.

Our analysis revealed that only a few links were common between the camps, and most of those were to user-generated content and unclassified content, followed by items from national media. This distribution differed greatly from that for links shared only within one camp. These findings support the Common Design Agenda, arguing that interventions should be developed to balance media consumption so as to reverse polarization. 


\begin{tabular}{|c|c|c|c|c|}
\hline \multicolumn{5}{|c|}{ Only within } \\
\hline & "pro" camp & “anti” camp & Common & Sig. \\
\hline National media & 28.82 & 36.77 & 9.78 & $\otimes \oplus \theta$ \\
\hline Local media & 2.53 & 5.10 & 1.60 & $\otimes \oplus \ominus$ \\
\hline Organization media & 0.68 & 0.17 & 0.19 & $\otimes \oplus$ \\
\hline Political party media & 2.79 & 3.11 & 0.93 & $\oplus \ominus$ \\
\hline International media & 8.08 & 2.71 & 0.17 & $\otimes \oplus \ominus$ \\
\hline News-like site & 1.34 & 17.89 & 0.69 & $\otimes \oplus \ominus$ \\
\hline Finnish NGO & 2.64 & 0.42 & 0.32 & $\otimes \oplus$ \\
\hline Finnish SM & 3.59 & 0.91 & 0.44 & $\otimes \oplus \ominus$ \\
\hline Finnish party & 0.39 & 0.43 & 0.08 & $\otimes \oplus \ominus$ \\
\hline International NGO & 0.36 & 0.30 & 0.03 & $\oplus \ominus$ \\
\hline International SM & 0.63 & 0.20 & 0.00 & $\otimes \oplus \ominus$ \\
\hline International party & 0.00 & 0.01 & 0.00 & \\
\hline Finnish GO & 1.10 & 0.61 & 0.28 & $\otimes \oplus \ominus$ \\
\hline International GO & 0.49 & 0.10 & 0.00 & $\otimes \oplus$ \\
\hline Multinational GO & 0.17 & 0.00 & 0.00 & $\otimes \oplus$ \\
\hline Person & 1.09 & 2.89 & 0.21 & $\otimes \oplus \ominus$ \\
\hline Company & 1.09 & 0.31 & 0.09 & $\otimes \oplus$ \\
\hline Organization & 1.04 & 0.10 & 0.00 & $\otimes \oplus$ \\
\hline UGC & 37.38 & 22.68 & 50.86 & $\oplus \ominus$ \\
\hline Unclassified & 5.80 & 5.29 & 34.35 & $\oplus \ominus$ \\
\hline$\sum$ & 100.01 & 100.00 & 100.02 & \\
\hline
\end{tabular}

Table 4: Links separated into common (shared in both camps) and shared only in the "pro" or "anti" camp (\%).

We will next examine the discourse that takes place in the comments posted below these links, to understand what kind of online discussion might emerge from a balanced news diet.

\section{RQ2: Discussion of Common Links Is More Opinion-Led}

Overall, the discussion was dominated by expressions of opinion (56\%), anecdotal statements (17\%), and questions $(10 \%)$. The type of statements made, however, differed between common links and single-camp links $\left(\chi^{2}=51.413\right.$, $d f=7, p<0.01)$.

The discussion below the common links was more opinionbased (see Table 5). In the non-common links' discussion, slightly below $50 \%$ of the comments made an evaluative remark, whereas the figure for the common' links discussion was slightly over $60 \%$. The overall odds ratio (1.2) is not enormous, owing to the opinion-driven nature of both discussion but does indicate a difference in the discussion styles. There are further differences in the type of statements made, with anecdotal and sourced statements being used less often in the common-link discussions. However, our rigorous statistical analysis did not allow us to confirm differences (for both, $p$ $>0.1$ ). Mobilization was much more active in the case of non-common links.

The opinion-driven aspect of the discussion was prominent irrespective of the camp. More than half of the posts and comments presented an opinion. Here, we should highlight that these opinions fairly often included antisocial elements, such as uncivil language. Sometimes they also included making a comparison to the other camp in a hostile manner. We did not extensively analyze these behaviors, but we can say that they were present in both the anti- and the pro-immigration camp.

These [comments] should not be read with too much focus. First, they are wrong and second they have been brainwashed.

\begin{tabular}{lrrl}
\hline & Common & Not common & Sig. \\
\hline Proposition & 6.0 & 6.4 & \\
Opinion & 61.3 & 49.4 & $\odot 1.2$ \\
Mobilization & 0.3 & 6.9 & $\odot 19$ \\
Question & 11.3 & 9.2 & \\
Anecdotal statement & 15.7 & 19.4 & \\
Personal experience & 3.6 & 3.9 & \\
Sourced statement & 3.6 & 6.9 & \\
Threat & 1.6 & 4.2 & \\
\hline Since each message could belong to more than one class, the figures do not add up to $100 \%$. \\
A significant difference of $\odot$ posts and comments with a common URL from posts and comments with a non-common \\
URL at $p<0.01$ with Bernoulli corrections.
\end{tabular}

Table 5: Classification of messages in conversations with a non-common link and common link (\%)

Phew, hell!!!!! But it's good if kids are taken away from people like that.... and the women also... I pity them!!!!

OMG, look the imagination and propaganda they have. Those who speak shit like that or publish it must be idiots.

These opinions could be backed up in various ways. We extended our analysis to separate anecdotal statements - statements presented as facts but with a source or other evidence to back up the arguments - from statements grounded in personal experience or referenced facts. The anecdotal experience was the most commonly used strategy to support the claims made in the text.

I've heard that in Spain there are areas where you can manage with the Finnish language only.

People who walk like this do have a severe identity problem or at least an unconscious inferiority complex.

Sourced statements were presented with links to provide additional support for the claims made. Sometimes these also included quoting a source, such as the law, directly inline in the comment.

As far as I understand, there are no (genetic) races within the human species, but it is a matter of social construction; i.e., biologically we are all "carved from the same tree." [link]

Another type of justification relied on participants' first-hand experience. Unlike in anecdotal evidence, commenters here clearly articulated how the evidence cited was collected, even though anecdotal.

I didn't see any [pejorative for immigrants] in the care home.

We are particularly interested in these types of justification that participants gave during the discussion. The great extent of anecdotal statements highlights the lack of more concrete rationale for the cause. Rather, it often seemed to present a particular reality felt by the posters that, because of its anecdotal nature, may be hard to challenge.

The rest of the categories (propositions, questions, mobilization, and threat scenarios) were present in only a few posts and could not be directly compared to other categories and across groups. Therefore, we do not go into these in this brief elaboration on our observations.

RQ2: Common Links Do Not Create a Common Ground In light of the opinion-driven nature of the links, it is interesting to examine how the camps reacted to common links. Therefore, we analyzed in detail the common links and classi- 


\begin{tabular}{lllll}
\hline & & \multicolumn{3}{c}{ "Pro" camp } \\
& & Support & Neutral & Opposition \\
"Anti” & Support & 1 & & $4^{\star}$ \\
camp & Neutrality & 1.5 & 0.5 & \\
& Opposition & 7.3 * & 1.3 & 0.3 \\
\hline
\end{tabular}

Table 6: Showing support and opposition with regard to a single common link in the sampled discussion

fied each message as supportive, neutral, or in opposition to the content behind the initial link.

We then summarized the thread on the basis of its largest count among these -i.e., the majority view of the posters on the issue. If such a majority was not found, we distributed the weight equally: if two views were equally prominent, a value of 0.5 was used and when all three views were "tied," 0.3 was used. Table 6 provides a summary of these findings; for example, we found a single case wherein both camps supported content justified by the same link.

The main finding, however, is that if one of the camps supported a link, the other camp disagreed with it. In Table 6, of the 16 cases examined, 11 showed this pattern (while one discussion had equal amounts of support, neutrality, and opposition) (see the cells marked with ${ }^{\star}$ ). This indicates that mere exposure to the other camp's perspective was not sufficient to adjust the opinion of the majority of participants to be more in line with the other participants. If this was the case, we would have seen more cases where both camps support or oppose the link.

The establishment of a common ground and appreciation to other perspectives and the other camp through shared news sources has however been one of the driving motivations behind the Common Design Agenda. Based on our qualitative analysis in RQ2, this is not supported by this empirical case. First, the discussion on the common links was more opinionated and often had hostility towards the other groups. Second, the common links did not create a shared understanding between these polarized groups, but rather lead to display of disagreement. Therefore, alternative design opportunities can be developed to mitigate polarization.

\section{CHALLENGING THE COMMON DESIGN AGENDA: RETHINKING THE DESIGN OPPORTUNITIES}

The common design agenda has been to propose "more balanced" news-reading among users or support social interaction over the camps. Our empirical observations, especially the observations on comments, showed that the common links do not bridge between people with opposing perspectives. They did not only fail to create common ground but often lead to display of high animosity towards the other camp. Therefore, designing socio-technical systems to decrease polarization must extend beyond balanced-information recommendations.

In this part of the work, we begin mapping the design opportunities for interventions which may decrease polarization. The aim here is to offer not fully formed design implications and the proposed opportunities do not relate to the empirical findings in the previous section. Rather, they aim to demonstrate that several alternative approaches can be used to address polit- ical polarization. This section should, therefore, be considered more as the initiation of a design framework to mitigate polarization, displaying that system design can go beyond balanced news-reading or supporting cross-camp social illustration.

\section{Re-implementation of Common Design Agenda}

Several systems developed focused on recommending "more balanced" news-reading $[52,10,40]$. The form of these interventions could be redeveloped in various ways, as elaborated below and seen on sketches in Figure 2. These ideas build upon the Common Design Agenda and its traditional implementation (see Figure Figure 2a). We have varied the format of the interventions to show the potential opportunities to reconsider how this intervention is done. Furthermore, we envision that these interventions - like the Common Design Agenda interventions - must be implemented so that no extra effort is required from the user to be exposed to them.

Aiming the intervention at the consumer or the poster Balanced news-reading systems are aimed at influencing the user's behavior during the consumption of media. However, the consumption phase in social media already includes framing for the given link. Therefore, suggesting alternative perspectives on a particular link will hardly break the framing supplied for it. When comparing discussion of the same stories between communities, we observed that discussion was uncivil and often questioned the opposing perspectives directly. Furthermore, we discussed that social media activity can be seen as strategic action, including the framing of shared news. Therefore, to mitigate polarization, also the poster who frames the link can be influenced. For example, the link-poster could be prompted with alternative views and news sites, thereby being given an opportunity to frame the story in a more nuanced manner (see Figure 2b). This is different from providing the reader with additional sources of information, which follows the Common Design Agenda (see Figure 2a).

The form of interaction: algorithmic or human-like The Common Design Agenda provides algorithmic intervention wherein the system aims to suggest alternative sources to users (see Figure 2a). For our case, we assume that the common links were not recommended by a system but picked up by users. Therefore, the users had already taken steps to break selective exposure, but the reactions were rather uncivil and even antisocial. We suggest various mechanisms to humanize the opposing camp through design practices should be investigated as tools to mitigate the most severe forms of targeted hate speech. One way to approach this could be to leverage the weak ties and show someone - a friend, relative, or friend of a friend - who has an opposite view, then summarize that person's perspective on the current issue. Naturally, this should be done in a manner respecting the platform's privacy settings and ensuring that the person used does not experience harm due to participation in this intervention. The intervention would give a face to, or humanize, "the other" (see Figure 2c).

Intervention content: links or discussions We consistently observed that the mere alternative perspectives provided through the links did not change posters' or commenters' ideological positions, which follows the Common Design Agenda (see Figure 2a). Intervention could focus also on showing emerging 


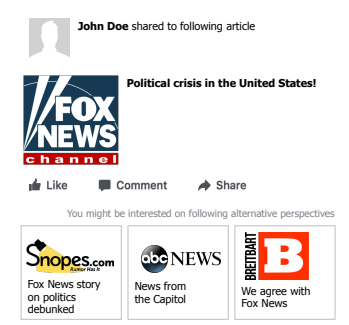

(a) The Common Design Agenda approach to intervention

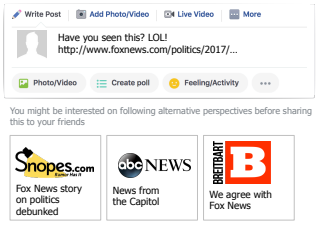

(b) Providing the intervention to the poster

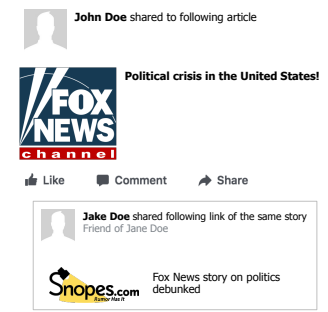

(c) Providing the intervention through another human

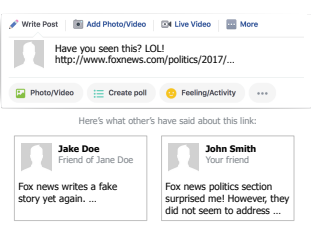

(d) Providing the intervention as discussion

Figure 2: Sketches - potential implementations of different intervention opportunities

discussions on the topic and, in this way, present the reader with a more balanced perspective on what people think and what the shared attitude is. For example, instead of alternative links, the system could show snippets of comments showing a different opinion on the topic being discussed (Figure 2d). We acknowledge that this potentially could lead to even more serious disagreement if the perspectives are too distant. Therefore, the selection of extracts shown should show a mix of supportive and opposing comment. Furthermore, the opposing comments should be taken not from ideological extremes which can already be seen as representing an enemy - but from people who belong to the middle ground.

The target of intervention The final design opportunity involves choosing the target for intervention. It has been shown that instead of extremist, interventions can be addressed on moderate participants in the discussion $[18,17]$. The may be more likely to react positively to this intervention.

\section{Beyond Common Design Agenda}

The common design agenda has also focused to develop recommendation systems (news recommendations, people recommendations), but another perspective would be to examine the discourse architecture [16], that is, examine if the sociotechnical setup of the conversation could be developed to mitigate polarization.

The works focused on supporting reflective listening and discussion, such as ConsiderIt [32, 33], can provide some initial ideas for such design. However, we should not expect such tools work directly in our case as the discussion is already polarized and, based on the comments we analyzed, strong dislike and mistrust towards the other camp. Recent work in political science has however proposed that this practice can also take place in enclaves, that is groups of like-minded populations [22]. However, to form like this, the discussion may

require facilitation, such as prompts which invite participants to consider different perspectives.

Furthermore, the spiral of silence-theory proposes that the people can avoid confrontation and not present perspectives which they believe are different from group majority viewpoints $[44,19,70]$. However, it may be that even within a single camp, opinions differ but are not expressed. Anonymity has been shown to address these kind of social concerns well (e.g., [45, 43]), but its negative implications for online discussion have also been established (e.g. [30, 49, 54, 55]). The discourse architecture can be developed in a way which allows the emergence of different viewpoints, for example allow expression of dislike of the post in an anonymous manner to make it visible to the group, allow building support to confrontation perspective within a smaller subgroup of each group, or present the estimated group level aggregate of support to particular perspectives based on latent features.

To conclude, we aim not to provide extensively designed insights but, rather, to suggest alternative ways to mitigate polarization and show that the community can do more than, following a core premise of previous work, i.e., merely give the reader an alternative set of news sites. Here, we must acknowledge that these designs present potentially sensitive data, positions on "hot" ideological topics, to people whose beliefs differ strongly. The privacy settings and the degree of political openness could be used to gauge which users might participate in such interventions. Furthermore, on a social media platform where commenting can take place, it is possible that these interventions would invite an attack on anyone that the system shows to disagree with the targeted individual. This means that the intervention should not allow direct interaction if it could be expected to create conflicts.

After these considerations, we remind that our aim with this section was to show, both in terms of rethinking the intervention or moving beyond and focus on the discourse architectures, that the there are several opportunities to aim mitigating polarization. While this is the case, the systems presented in human-computer interaction scholarship have focused on the intervention shown in Figure 2a. This indicates stagnation in terms of the design work which may limit the impact our community has to mitigate polarization.

\section{DISCUSSION}

Our work was motivated by a desire to rethink the design agenda for mitigating polarization in online social media. The common design agenda has involved increasing access to varied sources of information [52, 10, 40, 41, 42]. This approach has been prompted by link-sharing network analysis, which has consistently shown polarization taking place (e.g., in news sources between camps). Before engaging with the design agenda further, we summarize the findings presented above.

Firstly, we conducted an analysis not only of the domains but also of the media sources used by the pro- and antiimmigration camp via Facebook. We observed that the "pro" camp linked more actively to governmental organizations, social movements, and Finnish non-governmental organizations, and also companies, organizations, international media, and organization-media sites. Instead, the "anti" camp linked more 
to news-like sites and sites where the actual content is unclear from the domain (as with Dropbox content). These findings demonstrate that differences exist not only in the sites used as is well established - but also in the types of sites used.

To examine the common design agenda, we restricted our analysis to links shared in both camps. Only $2 \%$ of the full sample featured common links of this sort. ${ }^{2}$ We showed that the common links were different from links shared in either of the communities separately. The common links were more often to user-generated content (such as meme sites) or unclassified content. Our qualitative analysis revealed that the discussion threads on common links were more opinion-driven than discussions taking place on threads with a link shared only within a camp. Furthermore, we showed that the conversation on common links diverged: when one camp supported the goals behind the link, the other camp opposed them. Often the threads also led to antisocial behavior, attacks, and distrust for the other camp. Similar findings on the impact of biases have been made recently, in such contexts as raw-information processing when polarization is expected [47, 69]. The research indicates that personal biases are extremely strong and can distort decision-making.

Following we presented ways to reconsider the common design agenda to avoid stagnation in this critical area. We highlight that these should not be considered as fully articulated design ideas, but rather aim to show design opportunities which can in the future work be developed towards a design framework. Due to this, the design work does not "emerge" from the empirical findings. The empirical findings have informed us about challenges such as anti-social behavior and even de-humanization (and therefore, leads to proposals of human-like or discussion focused interventions), the goal with the design phase was to show that even minor changes to common design agenda lead to different forms of interventions. This is to demonstrate the stagnation on the common design agenda and make a call for reconsiderations.

\section{Future Work and Limitations}

Our work has been able to describe the polarization phenomenon and, through the qualitative work, provide critical insights for examining political communication via social media. However, that work is descriptive in nature and does not address the mechanisms that cause this behavior. For example, it has been shown repeatedly that between camps even reading scientific results becomes biased [69] Similarly, the mechanisms may be related to in-group and out-group classification phenomena, wherein members of one group must demonstrate that they differ from the other group [7]. Understanding the mechanisms would allow researchers to further examine design interventions. However, this cannot be achieved via an observational study such as ours and demands, for example, interviews. For instance, we could follow the approach that Semaan and colleagues [60] take, to understand what motivates participation.

\footnotetext{
${ }^{2}$ Regrettably, this number cannot be compared to international studies', since those have operated at a domain and not an URL level. The domain-level overlap is $15.5 \%$, which seems to be on par with Jacobson's study [27] but is significantly lower than that in the eliteblog study by Meraz [37]. Hence, the case we examine seems not to be an outlier but supported by international studies.
}

To develop the reconsidered design agenda further, experimental work must be used to investigate whether the suggested design opportunities would actually yield the intended effects, and with what parameters. With this type of work, the design proposals can be developed to a comprehensive design framework.

The findings are limited also by the scale of the data and context of the study. A simple suggestion would be to apply automated tools for data analysis. However, there have been recent concerns about the validity of automated tools to analyze politeness [25]. Therefore, we have chosen not to conduct this as using manual coding with acknowledging its limitations. Furthermore, the sample was limited for reason of concerns about the researchers' mental wellbeing. The total number of posts and comments was rather small $(1,520)$, and the analysis of support and opposition pairs by URL (see Table 6) included only 16 unique URL pairs (each having two or more discussion threads, with a total of 961 posts and comments). As with our research subjects, we aimed to limit exposure to harmful content on the researchers' part, and, with sufficient demonstration speaking to the results, we did not extend the coding beyond the $2 \%$ sample of common-link posts and comments.

Finally, the empirical case was clearly an extreme context of polarization. It may be that discussions with moderate participants may have lead to less anti social behavior and development of the common ground. The case, while being able to demonstrate potential harms of naïve recommendation systems, does not generalize across all potential discussions.

\section{CONCLUSION}

Researchers have proposed various content and person recommendation systems to mitigate effects of polarization and echo chambers. We aim to challenge this common design agenda both empirically and through design proposals. We have empirically examined the common design agenda by analyzing the links used in pro-immigration and anti-immigration communities and the discussions that emerged upon the posting of those links. We observed that on the domain level both camps most commonly used various news-media sources but overlap at the level of individual links were small. The overlap - links used by both pro-migration and anti-migration posters - is formed mainly of user-generated content, such as material on image-sharing sites and various social media platforms. We then turned to how links were discussed. We observed that much of the discussion was based on opinions and supported by anecdotal examples. We found that people had rather strong perspectives on the links and that they framed and discussed the links accordingly. Following this, we question the success of the common design agenda focused on recommendation systems. We demonstrate that the intervention can be designed in several ways and some of the proposals of which may succeed better to avoid the emergence of anti-social behavior more empirical work on this is required. Furthermore, the recommendation systems are not the only way polarization can be mitigated and we developed proposals to engage with a reconsideration of the design architecture. Based on the empirical work and the presentation of design proposals, we call for a reconsideration of the common design agenda. 


\section{REFERENCES}

1. Lada A Adamic and Natalie Glance. 2005. The political blogosphere and the 2004 U.S. election: divided they blog. In Proceedings of the 3rd international workshop on Link discovery. 36-43.

2. Pablo Barberá, John T. Jost, Jonathan Nagler, Joshua A. Tucker, and Richard Bonneau. 2015. Tweeting From Left to Right. Psychological Science 26, 10 (10 2015), 1531-1542. DOI : http://dx.doi .org/10.1177/0956797615594620

3. Åsa Bengtsson, Kasper Hansen, Ólafur P Harõarson, Hanne Marthe Narud, and Henrik Oscarsson. 2013. The Nordic voter: myths of exceptionalism. Ecpr Press.

4. S. Boulianne. 2015. Online news, civic awareness, and engagement in civic and political life. New Media \& Society (2015). DOI : http://dx.doi.org/10.1177/1461444815616222

5. Danah Boyd and Kate Crawford. 2012. Critical Questions for Big Data. Information, Communication \& Society 15, 5 (6 2012), 662-679. DOI :

http://dx.doi .org/10.1080/1369118X.2012.678878

6. Phil Brooker, John Vines, Selina Sutton, Julie Barnett, Tom Feltwell, and Shaun Lawson. 2015. Debating Poverty Porn on Twitter. In Proceedings of the 33rd Annual ACM Conference on Human Factors in Computing Systems - CHI '15. ACM Press, New York, New York, USA, 3177-3186. DOI: http://dx.doi.org/10.1145/2702123.2702291

7. Rupert Brown. 1988. Group processes: Dynamics within and between groups. Basil Blackwell.

8. Manuel Castells. 2011. The rise of the network society: The information age: Economy, society, and culture. Vol. 1. John Wiley \& Sons.

9. Manuel Castells and Pekka Himanen. 2002. The information society and the welfare state: The Finnish model. Number 250. Oxford University Press on Demand.

10. Sidharth Chhabra and Paul Resnick. 2012. Cubethat: news article recommender. In Proceedings of the sixth ACM conference on Recommender systems. ACM, 295-296.

11. Elanor Colleoni, Alessandro Rozza, and Adam Arvidsson. 2014. Echo Chamber or Public Sphere? Predicting Political Orientation and Measuring Political Homophily in Twitter Using Big Data. Journal of Communication 64, 2 (2014), 317-332. DOI :

http://dx . doi .org/10.1111/jcom. 12084

12. Russell J Dalton. 2008. The quantity and the quality of party systems: Party system polarization, its measurement, and its consequences. Comparative Political Studies 41, 7 (2008), 899-920.

13. Nicholas Diakopoulos and Mor Naaman. 2011. Towards quality discourse in online news comments. In Proceedings of the ACM 2011 conference on Computer supported cooperative work. ACM Press, New York, New
York, USA, 133. DOI :

http://dx.doi .org/10.1145/1958824.1958844

14. Eurostat. 2016. Asylum in the EU Member States Record number of over 1.2 million first time asylum seekers registered in 2015 Syrians, Afghans and Iraqis: top citizenships. Press release. (2016). http://ec.europa.eu/ eurostat/documents/2995521/7203832/3-04032016-AP-EN . pdf/790eba01-381c-4163-bcd2-a54959b99ed6

15. Morris P Fiorina and Samuel J Abrams. 2008. Political polarization in the American public. Annual Review of Political Science 11 (2008), 563-588.

16. Deen Freelon. 2015. Discourse architecture, ideology, and democratic norms in online political discussion. New Media \& Society 17, 5 (5 2015), 772-791. DOI: http://dx.doi.org/10.1177/1461444813513259

17. Kiran Garimella, Gianmarco De Francisci Morales, Aristides Gionis, and Michael Mathioudakis. 2016. Quantifying Controversy in Social Media. In Proceedings of the Ninth ACM International Conference on Web Search and Data Mining - WSDM '16. ACM Press, New York, New York, USA, 33-42. DOI : http://dx.doi.org/10.1145/2835776.2835792

18. Kiran Garimella, Gianmarco De Francisci Morales, Aristides Gionis, and Michael Mathioudakis. 2017. Reducing Controversy by Connecting Opposing Views. In Proceedings of the Tenth ACM International Conference on Web Search and Data Mining - WSDM '17. ACM Press, New York, New York, USA, 81-90. DOI: http://dx. doi .org/10.1145/3018661.3018703

19. Sherice Gearhart and WeiWu Zhang. 2015. "Was it something I said?" "No, it was something you posted!" A study of the spiral of silence theory in social media contexts. Cyberpsychology, Behavior, and Social Networking 18, 4 (2015), 208-213.

20. Eric Gilbert, Tony Bergstrom, and Karrie Karahalios. 2009. Blogs are echo chambers: Blogs are echo chambers. In System Sciences, 2009. HICSS'09. 42nd Hawaii International Conference on. IEEE, 1-10.

21. Tarleton Gillespie. 2012. The relevance of algorithms. In Media Technologies: Essays on Communication, Materiality, and Society. 167-194.

22. Kimmo Grönlund, Kaisa Herne, and Maija Setälä. 2015. Does Enclave Deliberation Polarize Opinions? Political Behavior 37, 4 (2015), 995-1020. D0I: http://dx.doi.org/10.1007/s11109-015-9304-x

23. Kimmo Grönlund. 2016. Eduskuntavaalit 2015. In Poliittisen osallistumisen eriytyminen. Eduskuntavaalitutkimus., Kimmo Grönlund and Hanna Wass (Eds.). Ministry of Justice, Finland.

24. K. A. Heatherly, Y. Lu, and J. K. Lee. 2016. Filtering out the other side? Cross-cutting and like-minded discussions on social networking sites. New Media \& Society (3 2016), 1461444816634677-. DOI : http://dx.doi .org/10.1177/1461444816634677 
25. Erin R Hoffman, David W. McDonald, and Mark Zachry. 2017. Evaluating a Computational Approach to Labeling Politeness. Proceedings of the ACM on Human-Computer Interaction 1, CSCW (12 2017), 1-14. DOI : http://dx.doi.org/10.1145/3134687

26. Juha V. A. Itkonen. 2015. Social ties and concern for global warming. Climatic Change 132, 2 (9 2015), 173-192. DOI : http://dx.doi.org/10.1007/s10584-015-1424-0

27. Susan Jacobson, Eunyoung Myung, and Steven L Johnson. 2016. Open media or echo chamber: the use of links in audience discussions on the Facebook Pages of partisan news organizations. Information, Communication \& Society 19, 7 (7 2016), 875-891. DOI : http://dx.doi .org/10.1080/1369118X.2015.1064461

28. Kathleen Hall Jamieson and Joseph N Cappella. 2008. Echo Chamber: Rush Limbaugh and the Conservative Media Establishment. Oxford University Press, Oxford. 320 pages.

29. Andreas Jungherr, Harald Schoen, and Pascal Jürgens. 2016. The Mediation of Politics through Twitter: An Analysis of Messages posted during the Campaign for the German Federal Election 2013. Journal of Computer-Mediated Communication 21, 1 (1 2016), 50-68. DOI : http://dx . doi .org/10.1111/jcc4.12143

30. Peter G. Kilner and Christopher M. Hoadley. 2005. Anonymity options and professional participation in an online community of practice. In Proceedings of the 2005 conference on Computer support for collaborative learning learning 2005. Association for Computational Linguistics, Morristown, NJ, USA, 272-280. DOI : http://dx. doi .org/10.3115/1149293.1149328

31. Rob Kitchin. 2014. Big Data, new epistemologies and paradigm shifts. Big Data \& Society 1, 1 (4 2014), 1-12. DOI : http://dx.doi.org/10.1177/2053951714528481

32. Travis Kriplean, Jonathan Morgan, Deen Freelon, Alan Borning, and Lance Bennett. 2012a. Supporting reflective public thought with considerit. In Proceedings of the ACM 2012 conference on Computer Supported Cooperative Work - CSCW'12. ACM Press, New York, New York, USA, 265. DOI : http://dx.doi.org/10.1145/2145204.2145249

33. Travis Kriplean, Michael Toomim, Jonathan Morgan, Alan Borning, and Andrew Ko. 2012b. Is this what you meant? Promoting listening on the Web with Reflect. In Proceedings of the 2012 ACM annual conference on Human Factors in Computing Systems - CHI '12. ACM Press, New York, New York, USA, 1559-1568. DOI : http://dx.doi .org/10.1145/2207676.2208621

34. J Richard Landis and Gary G Koch. 1977. The measurement of observer agreement for categorical data. biometrics (1977), 159-174.

35. Geoffrey C Layman, Thomas M Carsey, and Juliana Menasce Horowitz. 2006. Party polarization in American politics: Characteristics, causes, and consequences. Annu. Rev. Polit. Sci. 9 (2006), 83-110.
36. Eun-Ju Lee. 2012. That's Not the Way It Is: How User-Generated Comments on the News Affect Perceived Media Bias. Journal of Computer-Mediated Communication 18, 1 (10 2012), 32-45. DOI : http://dx.doi.org/10.1111/j.1083-6101.2012.01597.x

37. Sharon Meraz. 2015. Quantifying Partisan Selective Exposure Through Network Text Analysis of Elite Political Blog Networks During the U.S. 2012 Presidential Election. Journal of Information Technology \& Politics 12, 1 (1 2015), 37-53. DOI : http://dx.doi.org/10.1080/19331681.2014.974119

38. Solomon Messing and Sean J. Westwood. 2014. Selective Exposure in the Age of Social Media. Communication Research 41, 8 (12 2014), 1042-1063. D0I : http://dx.doi .org/10.1177/0093650212466406

39. Jonathan Scott Morgan, Cliff Lampe, and Muhammad Zubair Shafiq. 2013. Is news sharing on Twitter ideologically biased?. In Proceedings of the 2013 conference on Computer supported cooperative work CSCW'13. ACM Press, New York, New York, USA, 887. DOI : http://dx.doi.org/10.1145/2441776.2441877

40. Sean A Munson, Stephanie Y Lee, and Paul Resnick. 2013. Encouraging Reading of Diverse Political Viewpoints with a Browser Widget. In Proceedings of the Seventh International AAAI Conference on Weblogs and Social Media. 419-428.

41. Sean A. Munson and Paul Resnick. 2010. Presenting diverse political opinions. In Proceedings of the 28th international conference on Human factors in computing systems - CHI'10. ACM Press, New York, New York, USA, 1457-1466. DOI : http://dx.doi.org/10.1145/1753326.1753543

42. Sean A Munson, Daniel Xiaodan Zhou, and Paul Resnick. 2009. Designing interfaces for presentation of opinion diversity. Proceedings of the 27th international conference extended abstracts on Human factors in computing systems CHI EA 09 (2009), 3667-3672. DOI : http://dx.doi.org/10.1145/1520340.1520552

43. Matti Nelimarkka, Kai Kuikkaniemi, and Giulio Jacucci. 2014. A Field Trial of an Anonymous Backchannel Among Primary School Pupils. In Proceedings of the 18th International Conference on Supporting Group Work. ACM Press, New York, New York, USA, 238-242. DOI : http://dx.doi.org/10.1145/2660398.2660399

44. Elisabeth Noelle-Neumann. 1974. The spiral of silence a theory of public opinion. Journal of communication 24, 2 (1974), 43-51.

45. Jay F. Nunamaker, Robert O. Briggs, Daniel D. Mittleman, Douglas R. Vogel, and Balthazard A. Pierre. 1996. Lessons from a Dozen Years of Group Support Systems Research: A Discussion of Lab and Field Findings. Journal of Management Information Systems 13, 3 (12 1996), 163-207. DOI :

http://dx.doi.org/10.1080/07421222.1996.11518138 
46. Kieron O'Hara and David Stevens. 2015. Echo Chambers and Online Radicalism: Assessing the Internet's Complicity in Violent Extremism. Policy \& Internet 7, 4 (12 2015), 401-422. DOI:

http://dx.doi.org/10.1002/poi3.88

47. Stefano Palminteri, Germain Lefebvre, Emma J. Kilford, and Sarah-Jayne Blakemore. 2017. Confirmation bias in human reinforcement learning: Evidence from counterfactual feedback processing. PLOS Computational Biology 13, 8 (08 2017), 1-22. DOI : http://dx.doi.org/10.1371/journal.pcbi. 1005684

48. Emilia Palonen. 2017. Finland. European Journal of Political Research Political Data Yearbook (2017), 92-98. DOI : http://dx.doi .org/10.1111/2047-8852.12170

49. Zizi Papacharissi. 2004. Democracy online: civility, politeness, and the democratic potential of online political discussion groups. New Media \& Society 6, 2 (4 2004), 259-283. DOI : http://dx.doi.org/10.1177/1461444804041444

50. Eli Pariser. 2011a. The filter bubble: What the Internet is hiding from you. Penguin UK.

51. Eli Pariser. 2011b. The Filter Bubble: What the Internet Is Hiding from You. Penguin Press, New York. DOI : http://dx.doi.org/10.1353/pla.2011.0036

52. Souneil Park, Seungwoo Kang, Sangyoung Chung, and Junehwa Song. 2009. NewsCube: delivering multiple aspects of news to mitigate media bias. In Proceedings of the SIGCHI Conference on Human Factors in Computing Systems. ACM, 443-452.

53. James W Pennebaker, Martha E Francis, and Roger J Booth. 2001. Linguistic inquiry and word count: LIWC 2001. Mahway: Lawrence Erlbaum Associates 71, 2001 (2001), 2001.

54. Tom Postmes and Russell Spears. 1998. Deindividuation and antinormative behavior: A meta-analysis. Psychological Bulletin 123, 3 (1998), 238-259. DOI : http://dx.doi.org/10.1037//0033-2909.123.3.238

55. Tom Postmes, Russell Spears, Khaled Sakhel, and Daphne de Groot. 2001. Social Influence in Computer-Mediated Communication: The Effects of Anonymity on Group Behavior. Personality and Social Psychology Bulletin 27, 10 (10 2001), 1243-1254. DOI : http://dx.doi.org/10.1177/01461672012710001

56. Markus Prior. 2013. Media and political polarization. Annual Review of Political Science 16 (2013), 101-127.

57. Harto Pönkä. 2015. Ajankohtaista some-rintamalta: Facebook, Google+, Twitter ja Younited. https://harto.wordpress.com/2015/08/01/ajankohtaistasome-rintamalta-facebook-google-twitter-ja-younited/. (2015).

58. Ville Saarinen and Juho Ojala. 2017. The Flow towards Europe. https://www . lucify.com/the-flow-towards-europe/. (2017).
59. Bryan Semaan, Heather Faucett, Scott Robertson, Misa Maruyama, and Sara Douglas. 2015. Navigating Imagined Audiences: Motivations for Participating in the Online Public Sphere. Proceedings of the 18th ACM Conference on Computer Supported Cooperative Work \& Social Computing - CSCW'15 (2015), 1158-1169. DOI : http://dx.doi.org/10.1145/2675133.2675187

60. Bryan C. Semaan, Scott P Robertson, Sara Douglas, and Misa Maruyama. 2014. Social media supporting political deliberation across multiple public spheres. In Proceedings of the 17th ACM conference on Computer supported cooperative work \& social computing - CSCW '14. ACM Press, New York, New York, USA, 1409-1421. DOI : http://dx.doi.org/10.1145/2531602.2531605

61. M. M. Skoric, Q. Zhu, D. Goh, and N. Pang. 2016. Social media and citizen engagement: A meta-analytic review. New Media \& Society 18, 9 (2016), 1817-1839. DOI : http://dx.doi.org/10.1177/1461444815616221

62. Laurence Monnoyer Smith and Stèphanie Wojcik. 2012. Technology and the quality of public deliberation: a comparison between on and offline participation. International Journal of Electronic Governance 5, 1 (2012), 24-49. DOI :

http://dx.doi.org/10.1504/IJEG.2012.047443

63. Statistics Finland. 2006. Use of information and communications technology by individuals. http://www . stat. fi/til/sutivi/2016/index.html. (2006).

64. Jan Sundberg. 2014. Finland. European Journal of Political Research Political Data Yearbook 53, 1 (2014), 117-123. DOI : http://dx.doi.org/10.1111/2047-8852.12046

65. Jan Sundberg. 2015. Finland. European Journal of Political Research Political Data Yearbook 54, 1 (2015), 101-107. DOI : http://dx.doi.org/10.1111/2047-8852.12085

66. Cass R Sunstein. 2001. Republic.com 2.0. Princeton University Press., New Jersey.

67. Mike Thelwall, Kevan Buckley, Georgios Paltoglou, Di Cai, and Arvid Kappas. 2010. Sentiment in short strength detection informal text. Journal of the American Society for Information Science and Technology 61 (2010), q. DOI : http://dx.doi.org/10.1002/asi.21416

68. Mike Thelwall, Olga Goriunova, Farida Vis, Simon Faulkner, Anne Burns, Jim Aulich, Amalia Mas-Bleda, Emma Stuart, and Francesco D'Orazio. 2016. Chatting through pictures? A classification of images tweeted in one week in the UK and USA. Journal of the Association for Information Science and Technology 67, 11 (11 2016), 2575-2586. DOI : http://dx.doi .org/10.1002/asi . 23620

69. Anthony N. Washburn and Linda J. Skitka. 0. Science Denial Across the Political Divide. Social Psychological and Personality Science 0, 0 (0), 1948550617731500. DOI : http://dx.doi .org/10.1177/1948550617731500 
70. Brian E. Weeks, Daniel S. Lane, Dam Hee Kim, Slgi S. Lee, and Nojin Kwak. 2017. Incidental Exposure, Selective Exposure, and Political Information Sharing: Integrating Online Exposure Patterns and Expression on Social Media. Journal of Computer-Mediated Communication 22, 6 (2017), 363-379. DOI : http://dx.doi.org/10.1111/jcc4.12199

71. Jussi Westinen. 2016. Puoluevalinta Suomessa 2000-luvulla. In Poliittisen osallistumisen eriytyminen. Eduskuntavaalitutkimus., Kimmo Grönlund and Hanna Wass (Eds.). Ministry of Justice, Finland.

72. Jussi Westinen, Elina Kestilä-Kekkonen, and Aino Tiihonen. 2016. Äänestäjät arvo-ja asenneulottuvuuksilla. In Poliittisen osallistumisen eriytyminen. Eduskuntavaalitutkimus., Kimmo Grönlund and Hanna Wass (Eds.). Ministry of Justice, Finland.
73. Jung Hwan Yang, Hernando Rojas, Magdalena Wojcieszak, Toril Aalberg, Sharon Coen, James Curran, Kaori Hayashi, Shanto Iyengar, Paul K. Jones, Gianpietro Mazzoleni, Stylianos Papathanassopoulos, June Woong Rhee, David Rowe, Stuart Soroka, and Rodney Tiffen. 2016. Why Are "Others" So Polarized? Perceived Political Polarization and Media Use in 10 Countries. Journal of Computer-Mediated Communication 21, 5 (2016), 349-367. DOI :

http://dx.doi.org/10.1111/jcc4.12166

74. W. Zhang. 2015. Perceived Procedural Fairness in Deliberation: Predictors and Effects. Communication Research 42, 3 (2015), 345-364. DOI :

http://dx.doi.org/10.1177/0093650212469544 